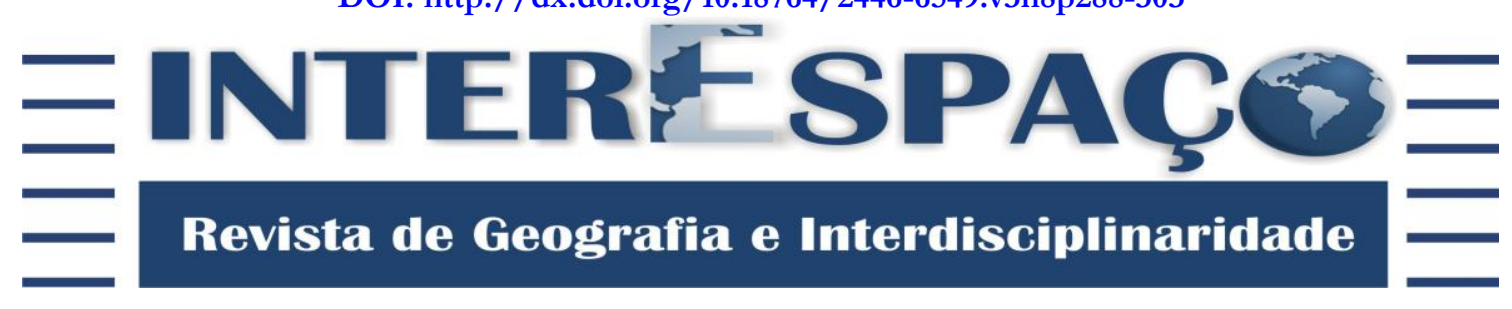

\title{
O DIÁLOGO HERMENÊUTICO NA ERA TÉCNICO- CIENTÍFICA: interlocuções entre Zygmunt Bauman e Hans-Georg Gadamer
}

\author{
THE HERMENEUTICAL DIALOGUE IN THE TECHNICAL-SCIENTIFIC \\ AGE: interlocutions between Zygmunt Bauman and Hans-Georg Gadamer
}

\section{DIÁLOGO HERMENÉUTICO EN LA ERA TÉCNICA: diálogos entre Zygmunt Bauman y Hans-Georg Gadamer}

\begin{abstract}
Natalia Mendes Teixeira
Graduada em Licenciatura em Ciências Humanas/Sociologia pela Universidade Federal do Maranhão - UFMA/Imperatriz. Mestranda em Filosofia pela Universidade do Vale do Rio dos Sinos - UNISINOS/RS. Bolsista: CAPES/PROSUP. natalia.nmt@gmail.com

Recebido para avaliação em 25/02/2017; Aceito para publicação em 17/04/2017.

\section{RESUMO}

O diálogo é central para o acontecer da experiência hermenêutica. Ela, enquanto linguagem, acontece no diálogo e este é o modo fundamentador e fundamental da hermenêutica. Mas como falar em diálogo hermenêutico numa sociedade cada vez mais monológica? Por isto, a tese deste trabalho é que a hermenêutica gadameriana pode, através do diálogo, da linguagem, e da fusão de horizontes, direcionar as relações modernas analisadas por Bauman, defendendo que o diálogo hermenêutico é possível, mesmo em um contexto dito pós-moderno, no qual estamos cada vez mais conectados e, aparentemente, cada vez menos nos compreendendo. Objetivaremos mostrar também que a preocupação de Gadamer sobre a monologização da vida foi extensamente tratada por Bauman, ao mesmo tempo em que as considerações de Gadamer são caríssimas às análises de Bauman.
\end{abstract}

Palavras-chave: Diálogo; Gadamer; Modernidade; Bauman.

\section{ABSTRACT}

The dialog is central to the happen of hermeneutic experience. This experience,as language happens on the dialog. This is the supporter and fundamental manner of hermeneutic. But how to speak about dialog in in an increasingly monological society? Therefore, the thesis of this paper is that the Gadamerian hermeneutic can through the dialog, the language and of the fusion of horizons direct the modern relations analysed by Bauman, arguing that hermeneutic dialogue is possible, even in a context as postmodern, in which we are increasingly connected and, apparently, less and less understanding ourselves. We aim to show as well that the worry of Gadamer about monologization of life was extensively treated by Bauman, at the same time as the considerations of Gadamer are very expensive to the analyzes of Bauman.

Keywords: Dialog; Gadamer; Modern; Bauman.

\section{RESUMEN}

El diálogo es central para que exista la experiencia hermenéutica. Ella, como lenguaje, existe en el diálogo y éste es el modo fundamentador y fundamental de la hermenéutica. Sin embargo, ¿cómo hablar de diálogo hermenéutico en una sociedad cada vez más monológica? Por esto, la tesis de este trabajo es que la hermenéutica gadameriana puede, a través del diálogo, del lenguaje, y de la fusión 
| Natalia Mendes Teixeira|

de horizontes, dirigir las relaciones modernas analizadas por Bauman, defendiendo que el diálogo hermenéutico es posible, incluso en un contexto conocido como posmoderno, en el cual estamos cada vez más conectados y en que parece que nos comprendemos cada vez menos. Objetivaremos mostrar también que la preocupación de Gadamer sobre la monologización de la vida fue extensamente tratada por Bauman, y al mismo tiempo, las consideraciones de Gadamer son valiosísimas para los análisis de Bauman.

Palabras clave: Diálogo; Gadamer; Modernidad; Bauman.

\section{INTRODUÇÃO}

A universalidade do problema hermenêutico está em todas as relações que dependem do acordo mútuo, pois a tarefa da hermenêutica, segundo Gadamer, é justamente encontrar a linguagem comum para a comunicação entre dois lados que falam línguas diferentes (GADAMER, 2002). Assim, a arte da compreensão não é aclamada somente para o trato com os textos, mas também com as pessoas. A hermenêutica filosófica é dada não como um instrumento, mas como uma postura, pois ela é um exercício metafísico e também ético baseado em pressupostos ontológicos ${ }^{1}$, sendo o diálogo central para essa experiência hermenêtica.

No entanto, na era da técnica e da comunicação virtual, de relações apressadas e utilitárias, quanto de diálogo - como unidade de sentido - há nas relações? Há possibilidade de uma abertura à dimensão do Tu, à perspectiva do outro, em emaranhamentos sociais cada vez mais centrados no Eu? Ou, trazendo as perguntas de Gadamer: a arte do diálogo está desaparecendo? Estamos assistindo a uma monologização crescente do comportamento humano? Será um fenômeno típico de nossa civilização que acompanha o modo de pensar técnico-científico? Estaríamos experimentando o Tu apenas como um objeto para si? Travados no primeiro tipo de experiência, proveniente da relação sujeitoobjeto das ciências naturais?

Com o acesso à informação, à tecnologia, com o desencaixe tempo e espaço, com a possibilidade de vincular-se aos iguais e desvincular-se dos diferentes em um clique, a linguagem e o diálogo, como dados intercambiáveis, estão comprometidos? Estaríamos cada vez mais falando diferentes línguas no mesmo ambiente? É possível abrir-se à dimensão do $T$, à perspectiva do outro, em contextos sociais cada vez mais centrados no Eu? Se o homem metropolitano moderno negocia com clientes, lida com empregados e contata pessoas de forma objetiva, onde cabe o diálogo hermenêutico nessas relações

\footnotetext{
1 Segundo Rohden (2002, p. 183), “não afirmamos apenas a natureza dialógica da linguagem, mas também uma constituição dialógica da existência. Ora, é isso que sustenta o fato de que o diálogo é um modo de ser e, enquanto postura é ontológico".
} 


\section{| Natalia Mendes Teixeira|}

puramente instrumentais? Como se pôr em diálogo efetivo, empático, aberto, em um ambiente cada vez mais monológico, ainda que conectado?

Essas perguntas não são novas, foram feitas por Gadamer ainda na década de 1970, antes da revolução cibernética e da geração de conectados: "a arte do diálogo está desaparecendo? $\mathrm{Na}$ vida social de nossa época não estamos assistindo a uma monologização crescente do comportamento humano? Será um fenômeno típico de nossa civilização que acompanha o modo de pensar técnico científico?” (GADAMER, 2002, p. 243).

Busco direcionar respostas a essas perguntas, inicialmente, com a análise feita pelas Ciências Sociais nas falas de Anthony Giddens (1991), Georg Simmel (1973), mas principalmente de Zygmunt Bauman (2004). Posteriormente, pretendo perceber sob quais aspectos a hermenêutica gadameriana pode direcionar essas relações através do diálogo, da linguagem, e da fusão de horizontes ${ }^{2}$, mesmo em um contexto dito pós-moderno, no qual estamos cada vez mais conectados e, aparentemente, cada vez menos nos compreendendo.

Há uma gama de características de nosso tempo que direcionam o diálogo, as quais poderiam ser aqui consideradas. Escolho dois aspectos que podem nos ajudar a pensar a capacidade para o diálogo hermenêutico do homem pós-moderno. O primeiro é uma análise do que Bauman considera "conexões humanas" na era da técnica, de laços fragilizados e relações líquidas e nas quais todas as coisas flutuam com velocidade sujeita à alteração algorítmica. O segundo aspecto é o da atitude blasé, desenhada por Georg Simmel como um mecanismo psicológico que desenvolvemos para lidar com a quantidade e intensidade dos estímulos exteriores que a vida na metrópole e nas cidades modernas nos provoca.

\section{RETRATOS DA MODERNIDADE: a fragilidade do diálogo moderno}

A história humana não tem uma forma homogênea e contínua de desenvolvimento, como se formasse uma mixórdia de aspectos que brotam de forma evolutiva. A pósmodernidade desestrutura essa visão da grand narrative que pretendeu narrar a história humana sob o aspecto evolutivo, como se encenássemos "um enredo dominante por meio do qual somos inseridos na história como seres tendo um passado definitivo, e um futuro

\footnotetext{
2 "A fusão se dá constantemente na vigência da tradição, pois nela o velho e o novo crescem sempre juntos" (GADAMER, 2002, p. 457). Embora esta relação seja dada precisamente na tensão entre o texto e o presente, isto pode ser lido como a necessidade de um comportamento hermenêutico.
} 


\section{| Natalia Mendes Teixeira|}

previsível” (GIDDENS, 1991, p. 12). Esses aspectos são desmanchados e refutados na sociedade moderna.

Da passagem de um período histórico a outro, não há transformação total e evolutiva como as narrativas da história linear sugerem. A história não é linear, é cíclica, e feita de rupturas e continuidades (BLOCH, 2001), aspectos contínuos e descontínuos. Estes últimos precisam ser percebidos para compreender as características que qualificam um momento histórico como diferente dos outros ${ }^{3}$. Portanto, ao se falar da pós-modernidade, é necessário perceber o que há de descontínuo que a desvencilha de momentos históricos anteriores. Para autores como Giddens, estamos nos desvencilhamos de um sistema baseado na manufatura de bens materiais para outro, relacionado mais centralmente com a tecnologia e com a informação (GIDDENS, 1991), entramos, portanto, na chamada era técnico-científica.

Um aspecto de descontinuidade e que interfere diretamente nas relações humanas, a partir da modernidade, começou com a separação tempo e espaço. Nas sociedades prémodernas, eles coincidiam totalmente. Estar temporalmente presente era estar espacialmente aqui e agora. A modernidade arranca o espaço do tempo, tornando possível relacionar-se prontamente com ausentes. O espaço é fantasmagórico e influenciado diretamente por aspectos distantes da localização topográfica, o que está fora do espaço também o estrutura. O tempo desconectado do espaço gera o esvaziamento de ambos, isto fomenta relações entre ausentes que estão localmente distantes da interação face a face (GIDDENS, 1991).

Esta separação levou ao chamado desencaixe social, que Giddens (1991, p. 29) referencia como "deslocamento das relações sociais de contextos locais de interação e sua reestruturação através de extensões indefinidas de tempo-espaço". Este aspecto instaurado na modernidade modifica indefinidamente as relações estabelecidas pelos indivíduos, possibilitando estabelecer contato com diversas pessoas ao mesmo tempo, em espaços distintos, possibilitando também um desvínculo abrupto. Por isso, podemos estar próximos e cada vez mais distantes, pois a facilidade em conectar-se é diretamente proporcional à possibilidade de desligar-se do outro. Os contatos são facilmente estabelecidos, e facilmente rompidos.

\footnotetext{
3 Para Gadamer também, o horizonte do presente não se dá à margem do passado, eles não estão desvinculados: "A fusão se dá constantemente na vigência da tradição, pois nela o velho e o novo crescem sempre juntos” (GADAMER, 2002, p. 457).
} 


\section{| Natalia Mendes Teixeira |}

À luz dessas considerações, o sociólogo polonês Zygmunt Bauman faz análises atomistas, e quase cirúrgicas. Suas referências à pós-modernidade ${ }^{4}$, metaforizada como líquida, ganharam corpo em diversas obras traduzidas para vários idiomas. Inspirada na clássica frase de Marx "tudo que é sólido se desmancha no ar" (BERMAN, 1986), a metáfora da liquidez, da fluidez e das substâncias referencia o mundo no qual nada é para durar. A solidez da sociedade feudal ou moderna foi ultrapassada, pois a modernidade ${ }^{5}$ líquida comporta uma sociedade que esvai, flui, pinga, extravasa, escorre, transborda pelo espaço e cujas características são dificilmente mantidas e contidas no recipiente do tempo.

$\mathrm{Na}$ obra Amor Líquido: sobre a fragilidade dos laços humanos, Bauman faz referências lúcidas às relações atuais referenciadas cada vez mais como "conexões" estabelecidas por uma "rede" - termos do mundo virtual que, segundo ele, tem se estendido às demais relações sociais. Tais conexões, que preenchem lacunas e ausências afetivas, não possuem garantia alguma de permanência, por isso os laços “precisam ser frouxamente atados, para que possam ser outra vez desfeitos, sem grandes delongas, quando os cenários mudarem — o que, na modernidade liquida, decerto ocorrerá repetidas vezes" (BAUMAN, 2004, p.9).

Assim, há uma crescente fragilização dos vínculos humanos, encenados por uma furiosa "individualização", por meio da qual os relacionamentos se tornam beneficies ambíguas, pois oscilam entre o desejo momentâneo e a descartabilidade possível: "No líquido cenário da vida moderna, os relacionamentos talvez sejam os representantes mais comuns, agudos, perturbadores e profundamente sentidos da ambivalência" (BAUMAN, 2004, p.10). Essa ambivalência é retratada pela indecisão entre a atração e a repulsão, pois em se tratando de relacionamento - romântico ou social - fica-se à espreita querendo - com o perdão da metáfora popular - comer o bolo e mantê-lo inteiro ${ }^{6}$.

Uma relação plausível é cada vez mais aquela que apenas satisfaz e não exige. Segundo a abordagem do sociólogo, trazemos a lógica do consumo para as relações. Ela se imprime até mesmo no relacionamento, supostamente livre, de objetificação, entre pais e filhos, pois, "esta é uma época em que um filho é, acima de tudo, um objeto de consumo emocional. Objetos de consumo servem a necessidades, desejos ou impulsos do

\footnotetext{
4 'Não basta criar novos termos como 'pós-modernidade', é necessário analisar o caráter e as consequências da própria modernidade" (GIDDENS, 1991, p. 12). Para este autor, ao invés de estarmos entrando, imediatamente e apenas, num período de pós-modernidade, podemos estar alcançando um período em que as consequências da modernidade estão se tornando mais radicalizadas do que antes.

5 Por entender que a pós-modernidade não é um desvínculo com a própria modernidade, utilizarei repetidas vezes tanto um termo quanto outro.

${ }^{6}$ Para ele, em nosso tempo, é cada vez mais “possível buscar 'relacionamentos de bolso' do tipo de que se 'pode dispor quando necessário' e depois tornar a guardar” (BAUMAN, 2004, p. 11).
} 


\title{
| Natalia Mendes Teixeira|
}

consumidor. Assim também os filhos” (BAUMAN, 2004, p. 43). Bauman não reduz o desejo de ter filhos a isso, mas salienta que essa relação familiar também recebe alcances da sociedade do consumo e da descartabilidade.

Mas, ao estabelecer uma "rede" em meio à multidão, garante-se que se estará conectado sempre que a multidão parecer obsoleta: "conexões são rochas em meio a areias movediças” (BAUMAN, 2004, p. 57). Para garantir tais conexões, mantemos os dedos ocupados - o celular é a segurança de não se estar só, afinal

\begin{abstract}
Há sempre mais conexões para serem usadas - e assim não tem grande importância quantas delas se tenham mostrado frágeis e passíveis de ruptura. $\mathrm{O}$ ritmo e a velocidade do uso e do desgaste tampouco importam. Cada conexão pode ter vida curta, mas seu excesso é indestrutível. Em meio à eternidade dessa rede imperecível, você pode se sentir seguro diante da fragilidade irreparável de cada conexão singular e transitória (BAUMAN, 2004, p. 57).
\end{abstract}

A efemeridade desses laços já não importa. Diante da quantidade possível, a qualidade se desmancha. Cortar a conexão aparenta ter mais importância que estabelecê-la, elas exigem menos tempo e esforço para serem estabelecidas e também para serem rompidas. A distância deixa de ser obstáculo para o contato; com a proximidade virtual, que separou comunicação e relacionamento ${ }^{7}$, é possível comunicar-se sem engajamento, sem estabelecer vínculo, conectar-se e desconectar-se em um clique:

Diferentemente da antiquada proximidade topográfica, ela não exige laços estabelecidos de antemão nem resulta necessariamente em seu estabelecimento. "Estar conectado" é menos custoso do que "estar engajado" — mas também consideravelmente menos produtivo em termos da construção e manutenção de vínculos (BAUMAN, 2004, p. 59).

Estamos nos conectando sem nos engajarmos. A intensa vida moderna torna as relações lógicas e instrumentalizadas. Se a vida no campo permitia um vínculo afetivo e emocional com todas as pessoas de uma comunidade, a vida na metrópole torna o homem embotado e vinculado a poucos. Não que ele não perceba as coisas à sua volta, mas que boa parte delas ele as planifique e as destitua de sua essência, ficando indiferente a alguns estímulos. Mas esse não é um problema que brota ontologicamente, ele se instala em nossas relações por conta da intensidade de excitações as quais estamos submetidos. Georg Simmel aponta que há um fenômeno psíquico que explica isso, um mecanismo de defesa que a vida na metrópole desencadeia:

${ }^{7}$ Uma coisa é comunicar-se instrumentalmente, outra é relacionar-se (BAUMAN, 2004). 
| Natalia Mendes Teixeira|

\begin{abstract}
Não há talvez fenômeno psíquico que tenha sido tão incondicionalmente reservado à metrópole quanto à atitude blasé. A atitude blasé resulta em primeiro lugar dos estímulos contrastantes que, em nítidas mudanças e compressão concentrada, são impostos aos nervos (...) Surge assim a incapacidade de reagir a novas sensações com a energia apropriada (...) A essência da atitude blasé consiste no embotamento do poder de discriminar. Isto não significa que os objetos não sejam percebidos, como é o caso dos débeis mentais, mas antes que o significado e valores diferenciais das coisas, e daí as próprias coisas, são experimentados como destituídos de substância. Elas aparecem à pessoa blasé num tom uniformemente plano e fosco; objeto algum merece preferência sobre outro (...) Como resultado dessa reserva, frequentemente nem sequer conhecemos de vista aqueles que foram nossos vizinhos durante anos. E é esta reserva que, aos olhos da gente da cidade pequena, nos faz parecer frios e desalmados (SIMMEL, 1973, p. 16 - grifo nosso).
\end{abstract}

Há elementos que o homem seleciona para dar atenção e relacionar-se em meio a inúmeros; os outros lhe aparecem com indiferença não por uma falha ética, mas por uma sobrecarga psicológica ${ }^{8}$. A atitude blasé possibilita a sobrevivência nos grandes centros. Ela pode barrar nosso diálogo com o diferente, encontrado a todo tempo, ou fragilizá-lo, torná-lo infértil.

No entanto, embora tais diagnósticos soem como uma apreciação negativa e pessimista da era da informação, não dá para reduzir uma provável inaptidão para a conversa empática à intensa vida na cidade, ou ao acesso tecnológico: "Seria tolo e irresponsável culpar as engenhocas eletrônicas pelo lento, mas constante recuo da proximidade contínua, pessoal, direta, face a face, multifacetada e multiuso" (BAUMAN, 2004, p. 60).

Se nós estamos cada vez mais conectados, e menos engajados com o outro, e vinculados afetivamente, este é um dado que altera frontalmente o acontecer da experiência hermenêtica. No entanto, a construção dos vínculos é uma necessidade humana, e não há como apenas afirmar que perdemos a capacidade de mantê-los. Embora a própria vida nos grandes centros traga uma invariável quantidade de estímulos externos que alteram psicologicamente a consciência e reações humanas ${ }^{9}$, não podemos reduzir a análise a isso; o logos nos pertence e nós somos qualificados como humanos por ele.

\title{
O LOGOS HUMANO, A LINGUAGEM E A CAPACIDADE PARA O DIÁLOGO
}

\footnotetext{
8 Segundo Simmel, o que planifica essa seleção e a direciona é a relação econômica - o dinheiro é o denominador comum dos valores afetivos, Ele "arranca irreparavelmente a essência das coisas, sua individualidade, seu valor específico e sua incomparabilidade" (SIMMEL, 1973, p. 18).

${ }^{9}$ Como registra Georg Simmel (1973, p.12): "Com cada atravessar de rua, com o ritmo e a multiplicidade da vida econômica, ocupacional e social, a cidade faz um contraste profundo com a vida de cidade pequena e a vida rural, no que se refere aos fundamentos sensoriais da vida psíquica".
} 


\section{| Natalia Mendes Teixeira|}

Gadamer afirma, pelo que aprendeu de Platão ${ }^{10}$, que a consciência científica moderna tem uma estrutura monológica que impede o pensamento filosófico de alcançar seus objetivos. Para ele, o diálogo pode ser desenvolvido como uma contraposição ao modelo científico-moderno de conhecimento, pois o diálogo hermenêutico tem pretensões maiores que esse modelo (ROHDEN, 2002). Assim, ele fundamenta a importância do diálogo, de uma abertura à experiência cônscia de suas pressuposições para dialogar com o outro (ROHDEN, 2008). Uma exposição à oposição que traga à tona nossos preconceitos. Ele parte da práxis ao conceito, implicando também a necessidade de considerar o outro a partir dele mesmo, abrindo-se à dimensão do outro.

Isso é possível porque o homem é o ser que possui a linguagem. Nos termos de Aristóteles, ele é dotado de logos (GADAMER, 2002), isto é, razão, pensamento. Sendo, portanto, animal rationale, ele se distingue dos demais, pois, através dessa distinção, ele consegue revelar ao outro o que lhe é bom, útil, nocivo, agradável. O que ele pensa ele pode comunicar, e formar um pensar partilhado, afiliar conceitos comuns, representando, compartilhando e comunicando um mundo objetivo.

O enigma da linguagem é que todo pensar sobre a linguagem está novamente arraigado pela linguagem, ao pensarmos, pensamos dentro de uma língua, nosso pensamento habita em uma língua, e este é o enigma da linguagem (sprache) posta em nosso pensamento. Mas a linguagem não é um instrumento que usamos e depois nos desfazemos, pois não há um estado de ausência da linguagem. Em todo saber, mesmo não externado, materializado, a linguagem já habita (GADAMER, 2002).

A linguagem tem três aspectos essenciais. Primeiro, o autoesquecimento implícito no ato de falar. Os aspectos da linguagem nos são fugidios e inconscientes durante a fala. Há um esquecimento de si durante o ato comunicativo. Tanto mais viva a comunicação, o ato da linguagem, menos consciente estamos dela. Há um esquecimento de si na linguagem. O segundo traço próprio da linguagem é justamente a ausência de um $e u$, pois que, se um fala o que só ele entende, não fala a ninguém: “falar significa falar a alguém. A palavra que é palavra vai ao encontro de alguém" (GADAMER, 2002, p. 179). Por isso, a linguagem não está no espectro do $e u$, mas na realidade do nós. A linguagem é realidade que une $e u$ e $t u$. O terceiro aspecto diz repeito à oniabrangência, universalidade da linguagem: "todo diálogo possui, portanto, uma infinitude interna e não acaba nunca” (GADAMER, 2002, p. 181).

\footnotetext{
10 A filosofia platônica liga-se ao cuidado com o outro como uma exigência da vida filosófica, colocando a filosofia não como um instrumento, mas como um modo de ser melhor. Assim como para Gadamer, a ciência não é para Platão um conhecimento somente teórico que se introduz instrumentalmente no sujeito.
} 


\section{| Natalia Mendes Teixeira|}

Uma enunciação é compreendida não só pelo dito, mas pelo não dito. A motivação de uma pergunta também direciona sua resposta, assim, "tanto no perguntar quanto no responder dá-se um diálogo infinito em cujo espaço se dá a palavra e a resposta. Tudo que é dito encontra-se nesse espaço" (GADAMER, 2002, p. 181). A referida linguagem e seus aspectos só existem no diálogo. Tal diálogo não é mero ruído social, mas também não se dá em um silêncio ensimesmado, embora a fala possa ser, em certo aspecto, dispensável para sua efetivação.

No texto $A$ incapacidade para o Diálogo (1972), acrescentado à obra Verdade e Método II, Gadamer discorre que o diálogo seria um acontecer entre pelo menos duas pessoas que têm em sua potência uma infinitude, mas que abarcam conjuntamente uma unidade singular. Esta habilidade humana deixa uma marca, algo expresso entre seus comunicadores. Ele não precisa incluir uma novidade de percurso, basta que possa ser experimentado algo no outro que ainda não havíamos encontrado em nossa experiência. Assim, o diálogo transforma, pois, se ele se desenvolve plenamente, fica algo no indivíduo que o transborda e direciona uma transformação.

O diálogo exerce várias funções na vida humana e sua fluência está no acontecer espontâneo da pergunta e da resposta, no que é dito e ouvido. O encontro de duas pessoas pelo diálogo é uma troca de experiências mediada por duas perspectivas, duas cosmovisões, duas imagens da realidade. Elas estão no mesmo mundo, mas não postas da mesma forma e, por isso, não possuem a mesma visão. Assim, o diálogo com o outro, ainda que se constitua uma atitude de desaprovação ou compreensão, é uma forma de expandir nossa individualidade que, junto com outras formam, ao fundo, um único universo de diálogo, universo já posto (GADAMER, 2002).

Ouvir de forma errada também faz parte dessa experiência, pois ouvir erroneamente é estar ouvindo a si próprio, seus impulsos e preocupações, deixando de ouvir efetivamente o outro. Gadamer conclui que a incapacidade é mais um confronto com aquele que não quer seguir nossas ideias que propriamente uma carência do outro. Mas através do diálogo ambos encontram o outro e também a si mesmo no outro.

Embora a hermenêutica em si não seja uma questão abordada por Bauman, ele faz considerações nitidamente gadamerianas a respeito da verdadeira habilidade para conversar ou capacidade para o diálogo denominado como sendo uma abertura ao que não nos é familiar:

Conversar com pessoas parecidas conosco é fácil, elas estão preparadas para aplaudir o que dizemos, são agradáveis e, antes de a conversa começar, elas já 
nos entendem. Mas discutir assuntos com pessoas que possuem diferentes pontos de vista, dos quais não gostamos, negociar algum tipo de acordo e de compromisso, um modus vivendi com essas outras pessoas, isso é uma habilidade (BAUMAN, 2016, s/p).

Bauman concorda com Gadamer que o diálogo com aqueles com os quais concordamos não nos exige tanto quanto abrir-se ao desconhecido e perceber-se numa interlocução com este. A habilidade não está em ser entendido e entender aqueles que já nos entendem; a aptidão para conversar está em saber e estabelecer comunicação com aqueles dos quais discordamos para, como diz Gadamer, que eu possa deixar valer em mim algo contra mim.

A habilidade para conversar expressa nossa humanidade e está para além da habilidade técnica em comunicação ou etiqueta (GEORGE, 2015). Essa capacidade possibilita responder adequadamente aos impulsos do compreender que nos confrontam em nossos envolvimentos. Ela é emblema da nossa possibilidade de nos abrir ao que não é nosso, envolver-nos com os outros para nos relacionarmos com eles na exterioridade de seu próprio ser e, assim, para que, ao conversarmos, ouçamos e falemos não apenas nos nossos termos, mas a partir das exigências de nosso encontro com eles (GEORGE, 2015).

\section{A EXPERIÊNCIA HERMENÊUTICA COMO ABERTURA PARA O OUTRO}

A teoria da experiência orientada para a ciência não alcança a historicidade, pois o intento da ciência é objetivar a experiência, escamando qualquer relação com o momento histórico. Nela, pretende-se que os experimentos sejam controlados, por isso a historicidade precisa ser desvinculada da experiência: "a experiência suspende em si mesma sua própria história e a extingue" (GADAMER, 2002, p. 512).

Experiência que é experiência atravessou expectativas. O experimentado é o consciente da própria finitude e das limitações do próprio tempo, experiência da própria historicidade. Ao falar da essência da experiência, ele demonstra três maneiras, historicamente efetivadas, de experimentar o outro, que também são maneiras transpostas para a tradição ${ }^{11}$. A experiência hermenêutica se faz na tradição e esta deve chegar à experiência. Mas a tradição não pode ser dominada pela experiência, ela é linguagem, fala por si, assim como um Tu, ele se comporta em relação ao objeto, mas não é objeto.

11 "A tradição é um verdadeiro companheiro de comunicação, ao qual estamos vinculados como o está o eu e o tu” (GADAMER, 2002, p. 528). 


\section{| Natalia Mendes Teixeira|}

A primeira atitude é entender o $T u$ como um objeto da ciência, pela análise comportamental, prevendo reações, portando-se de uma análise solipsista, voltada para si, detectando elementos típicos do comportamento e reduzindo o outro a estes, como se o outro fosse qualquer outro elemento com o qual temos contato, tendo essa tipificação como meio para nossos próprios fins, seria uma caracterização egoísta: conhecendo as pessoas através de sua conversão em objetos e retirando toda subjetividade.

Mas a segunda forma de experimentar o tu compreende o outro a partir de sua posição, como indivíduo, mas ainda como um referencial para si, ambicionando compreendê-lo melhor que a si próprio; é uma forma de compreender o outro antecipando-o. Este modo relacional tem uma aparência dialética, mas mediada pela reflexão de um sobre o outro; alguém sempre dominará o processo, e caímos no mesmo enredo histórico no qual estamos sempre lutando por reconhecimento ao atingir a dominação do outro; aqui o outro não é um objeto de cálculo, como no primeiro modo relacional, mas é um Tu a ser dominado, e não percebido em sua alteridade.

Há um terceiro meio que constitui a essência da experiência hermenêutica gadameriana e exige uma suspensão dos preconceitos, das antecipações e de toda sustentação prévia. A diferença essencial entre a segunda e a terceira é que esta última, defendida por Gadamer, viabiliza uma experiência com o Tu, reconhecendo que a tradição, o tu, o exercício de alteridade com o outro e com o texto tem algo a nos dizer. Esta seria a mais elevada maneira da experiência hermenêutica, na qual é necessário ouvir o Tu a partir dele próprio, uma abertura mútua para o outro que é infinito e não pode ser limitado aos meus conceitos prévios, à minha objetificação e nem a modelos prévios. Outro que é nova experiência, por isso estranheza e não familiaridade.

Assim, a experiência hermenêutica é dada como uma abertura para o outro, para a alteridade, o que configura numa crítica à relação sujeito-objeto das ciências naturais que passou a configurar um modo relacional também entre os indivíduos. A experiência científica, o modo matemático, dicotômico, pré-determinista e o foco em "descobrimentos" constantes levaram a um encobrimento do outro, a uma relação intersubjetiva, porém deficiente de um sujeito com o outro. Sujeito este que, diante do outro, entende-o partindo de sua própria perspectiva. Assim como a tradição, o tu não pode ser entendido como acontecimento dominável por meio da experiência. 


\section{| O diálogo hermenêutico na era técnico-científica: interlocuções entre Zygmunt Bauman e Hans-}

Georg Gadamer|

\section{| Natalia Mendes Teixeira|}

A compreensão histórica só é possível a partir da autocrítica, da percepção e da compreensão de que somente através do outro nos compreendemos. A história efeitual ${ }^{12}$ não está disponível ao controle do indivíduo, mas o indivíduo intérprete está sujeito a esta história, "pertencemos à história mais do que ela nos pertence" (GADAMER, 2002, p. 518). Assim, nosso conhecer precisa ser consciente de sua finitude. O intérprete está envolvido em um enredo histórico do qual não tem controle total.

Neste contexto, aquele que não quer se conscientizar de seus próprios preconceitos coíbe a reflexão da relação, alterando-a e destruindo sua vincularidade moral com o outro o mesmo acontece com relação à tradição. Faz-se necessário refletir sobre sua própria historicidade e estar imerso na tradição não restringe o saber, mas o movimenta, chegando à terceira forma de experiência que corresponde à essência da experiência hermenêutica

\section{A FUSÃO DE HORIZONTES ENTRE BAUMAN E GADAMER}

A experiência hermenêutica com o texto é em si um diálogo que orienta a verdade que se abre para com o texto (KOGLER, 2014). Embora esta relação seja referenciada precisamente na tensão entre o texto e o presente, entre o intérprete e a obra, isto pode ser lido como um comportamento hermenêutico que ilumina nossa relação com os outros. Afinal, a hermenêutica não é uma técnica de ler textos, ela é fundamental em todos os ambientes que dependem de acordos mútuos: "a tensão entre o horizonte do texto e o horizonte do leitor. É que chamo fusão de horizontes. Os horizontes separados como pontos de vista diferentes fundem-se num” (GADAMER, 2002, p. 405).

Mas, para entender o outro é necessário reconstruir o caminho dos próprios preconceitos e evitar a relação abstrata, a empatia individualizada, e entender que o outro que surge é um parceiro de comunicação, um outro de si, outro que é, ao mesmo tempo, diferente e próximo suficentemente para ser entendido, levado a sério sem recorrer, como mecanismo de negação, o tempo que pode levar a experiência de reconstrução das premissas do outro (KÖGLER, 2014).

Deste modo é que a voz do outro é levada em conta, como a representação cognitiva de alguém com o qual compartilho um horizonte, um interesse. Esse valor de abertura é o principal orientador que a interpretação requer, possibilitando modos de compreensão e de prática. É necessário evitar a visao instrumental que pretende estruturar

12 Para a análise da consciência da história efeitual, é necessário perceber que ela tem a estrutura do que chamamos aqui experiência (GADAMER, 2002). 


\section{| Natalia Mendes Teixeira|}

a atitude intersubjetiva que almeja atingir um conhecimento, o qual possa ser generalizável e que possa controlar o outro.

Bauman concorda inteiramente com Gadamer e cita, em diversas passagens, a abordagem deste sobre a "fusão de horizontes" como uma contracepção à incompreensão generalizada:

Como Hans Gadamer admiravelmente assinalou em seu Truth and method, a compreensão mútua é estimulada por uma "fusão de horizontes": os horizontes cognitivos, ou seja, aqueles estabelecidos e ampliados no curso da acumulação da experiência de vida. A "fusão" exigida pela compreensão mútua só pode resultar da experiência compartilhada (BAUMAN, 2007, p. 97 - grifo nosso).

Experiências compartilhadas podem resultar na fusão de horizontes. Compreender mutuamente e experimentar uma compreensão compartilhada são necessidades destacadas por Bauman, através de Gadamer, para viver e sobreviver às diferenças existentes na cidade; para ele, o locus dessa experiência é justamente o meio que borbulha os conflitos atuais, isto é, o meio urbano, ele é como um laboratório:

\footnotetext{
Laboratórios estes em que as formas de conviver com a diferença, ainda a serem aprendidas pelos habitantes de um planeta cada vez mais populoso, são a cada dia, mais inventadas, testadas, memorizadas e assimiladas. O trabalho da "fusão de horizontes" de Gadamer, aquela condição necessária do allgemeine Vereinigung der Menschbeit de Kant, pode muito bem começar no palco urbano. Nesse palco, a apocalíptica visão de Huntington do conflito inconciliável e do inescapável "choque de civilizações" pode ser traduzida em encontros diários benignos, e muitas vezes profundamente gratificantes e agradáveis, com a humanidade que se esconde por trás das máscaras teatrais assustadoramente estranhas de raças, nacionalidades, deuses e liturgias diferentes e exóticas. Mais que em qualquer outro lugar, é nas ruas compartilhadas das cidades que se pode descobrir e aprender (BAUMAN, 1998, p. 98 - grifo nosso).
}

Na cidade globalizada, os diferentes se encontram e se estranham. Mas há nessas relações uma humanidade que se esconde por trás das diferenças, tanto de nacionalidades, religião ou de assentimentos exóticos, e que podem resultar em encontros transformadores e agradáveis. Tanto para Bauman quanto para Gadamer, a aptidão para a conversa, o compartilhamento de experiências que possibilitem a fusão de horizontes, a abertura de um único universo de diálogo podem ser cultivados em tempos de difusão da função delete, em contextos urbanos cada vez mais arrojados, e no quais o diferente está cada vez mais próximo.

\section{CONCLUSÃO}




\section{| Natalia Mendes Teixeira|}

A interlocução entre duas áreas de conhecimento pode ser recebida com obstinação e isto claramente é produto de uma ciência monológica, cada vez mais especializada e de visão encerrada, a qual não se propõe discutir e interpretar temas paralelos com outras áreas de conhecimento. Mas vimos que a preocupação de Gadamer sobre a informatização e monologização da vida foi extensamente tratada por Bauman, ao mesmo tempo, as considerações de Gadamer são caríssimas às análises de Bauman.

Analisamos como a proximidade virtual desvinculou comunicação e relacionamento, tornando possível comunicar-se sem engajamento, sem estabelecer vínculo, bem como conectar-se e desconectar-se repentinamente. Estamos nos conectando sem nos engajarmos e boa parte das relações diárias é mais lógica, objetiva e instrumentalizada que afetiva, das quais nem as relações familiares escapam.

Mas Bauman chega à mesma conclusão que Gadamer, para o qual sempre haverá uma forma de entendimento entre seres racionais. O diálogo hermenêutico pode ter se enfraquecido ou se transformado na era técnico-científica. Mas ele não está necessariamente impossibilitado, pois, se o homem é o único ser dotado de logos, que possui uma linguagem, que é pensamento, e que ela não é um mecanismo do qual se pode desfazer, mas que faz parte da constituição humana, então a capacidade para o diálogo sempre pode ser desenvolvida.

Perguntamos inicialmente se há possibilidade de uma abertura à perspectiva do outro em emaranhamentos sociais cada vez mais centrados no Eu. Então lembramos, juntamente com Gadamer, que a linguagem, constituinte do ser humano, tem um aspecto de esquecimento de si, de ausência de um eu. Vimos que ela tem um aspecto de universalidade que traz ao diálogo uma infinitude interna que não termina. Por isso, a linguagem não está no espectro do $e \varkappa$, mas na realidade do nós. A linguagem é realidade que une eu e $t u$. Somos postos no mesmo mundo, mas não da mesma forma e com a mesma perspectiva. Por isso, o diálogo com o outro é uma forma de expandir nossa individualidade, expormo-nos ao oposto, conscientizarmo-nos de nossos preconceitos e formarmos um único universo de diálogo. E que compartilhar experiências possibilita a fusão de horizontes.

A incapacidade para o diálogo é entendida, por Gadamer, mais como um embate com aquele que não quer seguir o que pensamos que uma carência do outro, ou uma deficiência social generalizada em determinado tempo histórico ${ }^{13}$. Pelo diálogo, encontramos um ao outro e também a si mesmo no outro. Como vimos, a não abertura ao

13 A “incapacidade para o diálogo parece-me ser mais objeção que se lança contra aquele que não quer seguir nossas ideias do que uma carência real no outro” (GADAMER, 1972, p. 252). 
| O diálogo hermenêutico na era técnico-científica: interlocuções entre Zygmunt Bauman e HansGeorg Gadamer|

| Natalia Mendes Teixeira|

outro está muitas vezes na relação com os próximos do dia a dia, mas que estão posicionados no mundo de maneira diferente da nossa, e por isso assumem perspectivas diferentes.

Com a variedade de meios de transportes, difusão da tecnologia, com o transculturalismo, a formação de uma aldeia global de sistemas cosmopolitas, os desencaixes sociais, deslocamento espaço-temporal, o surgimento dos sistemas peritos ${ }^{14} \mathrm{e}$ conurbações culturais, os diferentes se encontram diariamente, compartilham experiências e podem, sim, compartilhar perspectivas, dialogar e fundir horizontes. Essa é uma tarefa do hermeneuta para Gadamer e é uma necessidade do homem urbano, para Bauman.

\section{REFERÊNCIAS}

BAUMAN, Zygmunt. Comunicação Líquida. Revista Comunicação Empresarial, 26 jan. 2015. Entrevista. Disponível em: <http://www.fronteiras.com/entrevistas/zygmuntbauman-comunicacao-liquida-1424952791>. Acesso em: 30 nov. 2016.

Amor Líquido: sobre a fragilidade dos laços humanos. Rio de Janeiro: Jorge Zahar Ed., 2004.

Tempos líquidos. Rio de Janeiro: Jorge Zahar Ed., 2007.

O mal-estar da pós-modernidade. Rio de Janeiro: Jorge Zahar Ed., 1998.

BERMAN, Marshall. Tudo que é sólido desmancha no ar. Tradução de Carlos Felipe Moisés. São Paulo: Editora Schwarcz, 1986.

BLOCH, Marc. Apologia da história ou o ofício do historiador. Rio de Janeiro: Zahar Editora, 2001.

GADAMER, Hans-Georg. Verdade e Método I: traços fundamentais de uma hermenêutica filosófica. 6. ed. Petrópolis, RJ: Vozes, 2004.

GADAMER, Hans-Georg. Verdade e Método II: complementos e índices. 15. ed. Petrópolis, RJ: Vozes, 2002.

GEORGE, Theodore. The Responsibility to Understand. Phenomenological Perspectives on Plurality, Cambridge, p. 103-120, 2015.

GIDDENS, Anthony. As consequências da modernidade. Tradução de Raul Fiker. São Paulo: Editora UNESP, 1991.

${ }^{14}$ Segundo Giddens, "Por sistemas peritos quero me referir a sistemas de excelência técnica ou competência profissional que organizam grandes áreas dos ambientes material e social em que vivemos hoje (...) eles fornecem garantias de expectativas através do tempo-espaço distanciado” (GIDDENS, 1991, p.35/36.). 
| O diálogo hermenêutico na era técnico-científica: interlocuções entre Zygmunt Bauman e HansGeorg Gadamer|

| Natalia Mendes Teixeira|

KOGLER, Hans-Herbert. The crisis of hermeneutic ethic. Philosophy Today, v. 58, issue 1, winter 2014.

ROHDEN, Luiz. Hermenêutica Filosófica. São Leopoldo, RS: Unisinos, 2002.

ROHDEN, Luiz. Interfaces da Hermenêutica: método, ética e literatura. Caxias do Sul, RS: Educs, 2008.

SIMMEL, Georg. A metrópole e a vida mental. In: VELHO, Otávio Guilherme (Org.). O fenômeno urbano. Tradução de Sergio Marques dos Reis. 2. ed. Rio de Janeiro: Zahar Editores, 1973. p. 11-25. 